\title{
SISTEMA MICROFLUÍDICO PARA PRODUÇÃO DE NANOPARTÍCULAS DE QUITOSANA GLICOSILADA E TRIPOLIFOSFATO DE SÓDIO
}

\author{
T. D. MUSTAFÁ ${ }^{1}$, A. C. S. N. PESSOA ${ }^{1}$, G. PERLI ${ }^{1}$, C. C. SIPOLI ${ }^{1,2}$ e L. G. de LA \\ TORRE $^{1}$ \\ ${ }^{1}$ Universidade Estadual de Campinas, Faculdade de Engenharia Química \\ ${ }^{2}$ Universidade Tecnológica Federal do Paraná, Engenharia Química \\ E-mail para contato: latorre@ feq.unicamp.br
}

\begin{abstract}
RESUMO - A quitosana é um biopolímero cationico amplamente utilizado nas áreas farmacêutica e médica. A partir da glicosilação a quitosana apresenta uma maior aplicabilidade biológica por apresentar-se totalmente solúvel em água com pH neutro. Nanopartículas de quitosana podem ser obtidas por várias técnicas, dentre as quais destaca-se a microfluídica, que utiliza dispositivos capazes de processar pequenas quantidades de fluidos, permitindo operações contínuas e processos reprodutíveis. Este trabalho tem como principal objetivo o estudo da produção de nanopartículas de quitosana glicosilada utilizando o agente reticulante tripolifosfato de sódio para futuras aplicações em gene delivery. Para isso, estudou-se um dispositivo microfluídico de focalização hidrodinâmica de geometria longa, empregando uma corrente central de água e correntes laterais formadas por soluções de quitosana glicosilada e tripolifosfato de sódio. A caracterização físico-química das nanopartículas foi realizada em termos de potencial zeta, tamanho e polidispersidade. Avaliou-se a influência do $\mathrm{pH}$ na formação de nanopartículas e as características mais favoráveis foram obtidas em condições ácidas (pH 4). Nesse caso, para uma concentração final de quitosana glicosilada de $0,4 \mathrm{mg} / \mathrm{mL}$, foram produzidas nanopartículas com índice de polidispersidade de 0,03 $\pm 0,02$ e $242 \pm 2 \mathrm{~nm}$ de diâmetro médio.
\end{abstract}

\section{INTRODUÇÃO}

Nos últimos anos, nanopartículas de quitosana têm mostrado grande aplicabilidade para os processos de veiculação de fármacos e ácidos nucleicos (drug e gene delivery) (Fan et al., 2012). A terapia gênica consiste na introdução de ácidos nucleicos ao material genético intracelular do paciente a fim de induzir a produção de proteínas específicas, inibir a indução de um gene específico ou reverter mutações gênicas indesejáveis (Jeong et al., 2007). O interesse na aplicação de polímeros naturais, em especial a quitosana (CHI), como vetores não virais de terapia gênica aumentou significativamente na última década por apresentarem diversas vantagens sobre compostos sintéticos, como baixa toxicidade, biocompatibilidade e biodegradabilidade (Bulmer et al., 2012).

No entanto, a aplicação de quitosana em sistemas biológicos é dificultada, pois seu grupo amino primário apresenta um valor de pKa de 6,5 e, consequentemente, a molécula é 
insolúvel em água em pH fisiológico (7,4) (Strand et al., 2008). Por sua vez, a quitosana glicosilada (GlyCHI) possui uma maior aplicabilidade biológica por apresentar-se totalmente solúvel em água com pH neutro (Yu et al., 2008). Strand et al. (2008) comprovaram a eficácia de transfecção celular, ou seja, de entrega intracelular de ácidos nucleicos de interesse, a partir de oligômeros formados de GlyCHI.

Nanopartículas de quitosana podem ser produzidas por vários métodos, sendo que a gelificação ionotrópica está entre os mais utilizados. Essa técnica baseia-se na interação eletrostática da quitosana com polieletrólitos de íons opostos. Um poliânion bastante utilizado é o tripolifosfato de sódio (TPP) (Carrillo et al., 2014). Além disso, a produção de nanopartículas por meio de dispositivos microfluídicos também vem sendo estudada. A microfluídica é caracterizada pelo estudo e manipulação de fluidos em escala micrométrica (Whitesides, 2006) e permite a síntese de nanopartículas com composição, morfologia, tamanho e distribuição de tamanho em processos reprodutíveis (Hasani-Sadrabadi et al., 2012; Karnik et al., 2008). Deste modo, a microfluídica emerge como tecnologia promissora no desenvolvimento de processos para a produção de nanopartículas de quitosana.

Nesse contexto, o objetivo deste trabalho foi explorar os parâmetros operacionais de produção de nanopartículas de quitosana glicosilada utilizando o agente reticulante tripolifosfato de sódio em sistemas microfluídicos para futuras aplicações em terapia gênica.

\section{MATERIAIS E MÉTODOS}

\subsection{Materiais}

Quitosana glicosilada (GlyCHI) e tripolifosfato pentasódico (TPP), adquiridos da empresa Sigma Aldrich. Ácido acético glacial adquirido da Labsynth (Diadema, SP, Brasil). Para construção dos dispositivos microfluídicos, utilizou-se o Sylgard 184 Elastomer Kit da Dow Corning (Midland, MI, EUA).

\subsection{Métodos}

Produção dos dispositivos: Os dispositivos foram construídos a partir de litografia macia em polidimetilsiloxano (PDMS), sendo selados com vidro através de plasma de $\mathrm{O}_{2}$. Os microcanais apresentaram dimensões retangulares com $140 \mu \mathrm{m}$ de largura e aproximadamente $50 \mu \mathrm{m}$ de altura. Os microdispositivos foram preparados no Laboratório de Microfabricação no Centro Nacional de Pesquisa em Energia e Materiais - CNPEM. Para este estudo, avaliouse o dispositivo de focalização hidrodinâmica de geometria longa (Figura 1).

Produção das nanopartículas de quitosana: Com auxílio de bombas seringa do modelo PHD2000 (Infuse/Withdraw) da Harvard Apparatus, soluções de GlyCHI e TPP foram injetadas nas correntes laterais do dispositivo microfluídico, e água ultrapura foi inserida na corrente central (Figura 1). A razão entre a soma das vazões das correntes laterais com relação à vazão da corrente central foi definida pelo valor de FRR (Flow Rate Ratio).

Caracterização físico-química das nanopartículas: A caracterização das nanopartículas foi feita em termos de: (i) diâmetro médio e índice de polidispersidade (PDI), através da técnica de espalhamento de luz dinâmico, e (ii) densidade de carga (potencial zeta), utilizando equipamento Zetasizer Nano ZS da Malvern Instruments. 
Figura 1 - Esquema ilustrativo do dispositivo microfluídico de focalização hidrodinâmica de geometria longa utilizado na produção de nanopartículas de GlyCHI e TPP. No detalhe, é

possível observar o ponto de focalização das correntes.

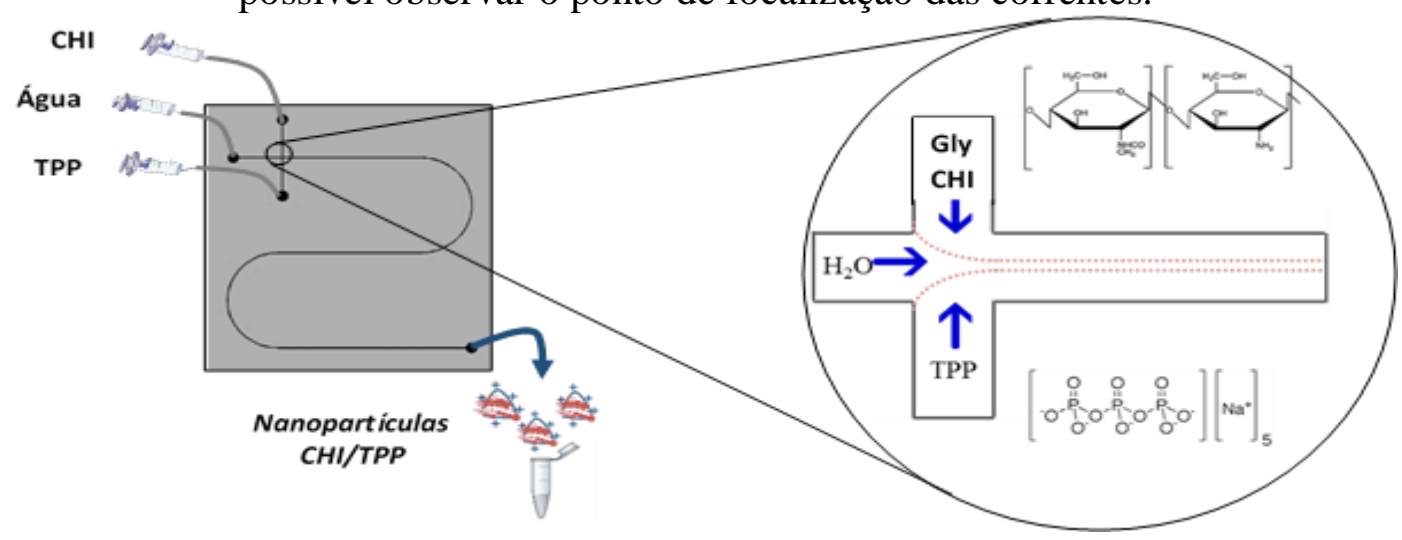

\section{RESULTADOS E DISCUSSÃO}

Para o processo de produção de nanopartículas desenvolvido neste trabalho, o valor de FRR foi mantido constante e igual a 1,3, correspondente à vazão de cada corrente lateral ambas iguais a $25 \mu \mathrm{L} / \mathrm{min}$, e à vazão da corrente aquosa central de $40 \mu \mathrm{L} / \mathrm{min}$. As outras variáveis operacionais envolvidas, como a relação mássica $\left(\mathrm{R}_{\mathrm{GlyCHI} / \mathrm{TPP}}\right)$ entre GlyCHI e TPP, as concentrações das soluções de GlyCHI e TPP e o pH das soluções utilizadas foram estudadas a fim de se obter as melhores condições operacionais.

\subsection{Estudo da razão mássica entre GlyCHI e TPP $\left(\mathbf{R}_{\mathrm{GlyCHI} / \mathrm{TPP}}\right)$ em $\mathbf{p H} 7$}

Para avaliar a formação de nanopartículas de GlyCHI e TPP, o pH das soluções de água, GlyCHI e TPP foi mantido em 7, tendo em vista que a GlyCHI é solúvel neste pH. Após estudo prévio das condições de processo, a concentração final de GlyCHI foi fixada em 0,4 $\mathrm{mg} / \mathrm{mL}$. Os resultados da análise dessas amostras encontram-se nas figuras 2 (A) e 2 (B).

Figura 2 - Valores de (a) Diâmetro médio (ponderado por número) e Índice de Polidispersidade (PDI) e (b) Potencial Zeta (mV) obtidos a partir de nanopartículas produzidas para diferentes valores de relação mássica ( $\left.\mathrm{R}_{\mathrm{GlyCH} / \mathrm{TPP}}\right)$ em $\mathrm{pH} 7$.

(A)

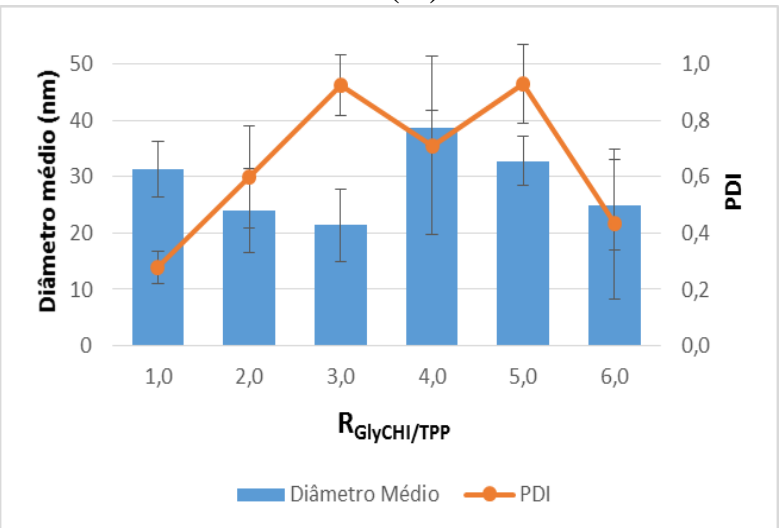

(B)

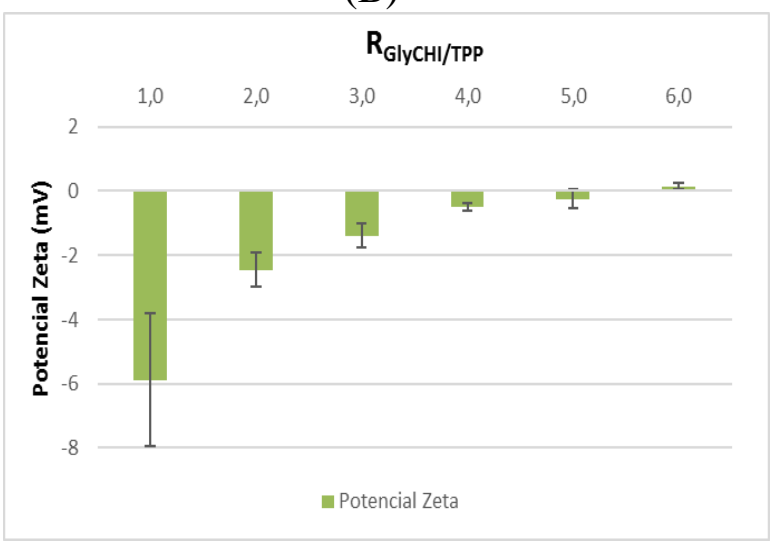


Como pode-se observar pela Figura 2, os valores de diâmetro médio das nanopartículas apresentaram valores muito próximos entre si e não seguiram alguma tendência com relação aos valores de $\mathrm{R}_{\mathrm{GlyCH} / \mathrm{TPP}}$. O potencial zeta das soluções coletadas aumentou com o valor de $\mathrm{R}_{\mathrm{GlyCH} / \mathrm{TPP}}$, como era esperado pelo aumento das cargas positivas provenientes dos grupos amino da GlyCHI (Lee et al., 2004), porém apresentou-se negativo ou muito próximo de zero. Esse fator pode limitar a aplicabilidade biológica das nanopartículas produzidas, pois, além de não apresentarem estabilidade coloidal, os valores positivos de potencial zeta seriam desejáveis para aplicações de gene delivery, considerando a interação entre os vetores não virais catiônicos e a membrana celular negativa (la Fuente, de et al., 2008).

Além disso, o índice de polidispersidade das partículas formadas apresentou-se elevado independentemente da razão mássica, chegando próximo a 1,0 em alguns casos. Com base nesses resultados, considerou-se que as partículas produzidas não se mostraram apropriadas para futuras investigações. Deste modo, estudou-se a influência do pH das soluções de água, GlyCHI e TPP para a produção de nanopartículas.

\subsection{Estudo do efeito do pH na produção das nanopartículas}

Para avaliar o efeito do $\mathrm{pH}$ nas características das nanopartículas de GlyCHI/TPP, as soluções de água, GlyCHI e TPP tiveram o pH ajustado para 4. A hipótese estabelecida para essa investigação foi de garantir que os grupamentos amina mantivessem sua característica catiônica, pela redução do pH, para favorecer as interações com o TPP. Nesse caso, mantevese a condição do estudo anterior de concentração final de GlyCHI em $0,4 \mathrm{mg} / \mathrm{mL}$ e adotou-se o valor de $\mathrm{R}_{\mathrm{GlyCHI} / \mathrm{TPP}}$ igual a 2 . As características das amostras coletadas foram comparadas com os resultados obtidos no item anterior para $\mathrm{R}_{\mathrm{GlyCHI} / \mathrm{TPP}}$ igual a 2, como apresentado nas Figuras 3 (A) e 3 (B).

Figura 3 - Valores de (A) Diâmetro médio e PDI (linha vermelha apenas para facilitar a vsualização) e (B) Potencial Zeta $(\mathrm{mV})$ para nanopartículas produzidas nos $\mathrm{pHs} 4$ e 7 com concentração final de GlyCHI igual a $0,4 \mathrm{mg} / \mathrm{mL}$ e $\mathrm{R}_{\mathrm{GlyCH} / \mathrm{TPP}}$ igual a 2 .

(A)

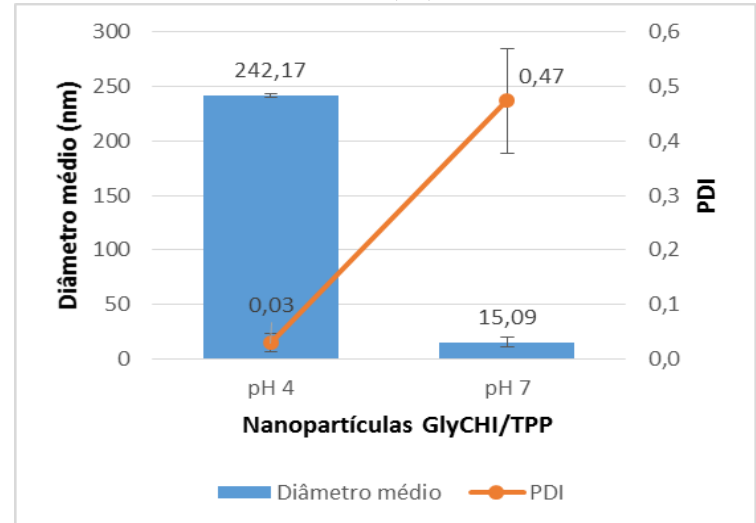

(B)

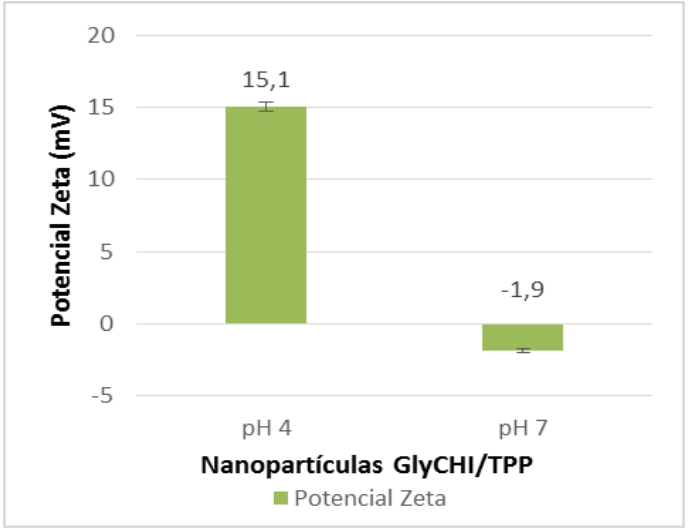

$\mathrm{O}$ estudo da variação de $\mathrm{pH}$ das soluções demonstrou uma grande influência sobre as características das partículas produzidas. Quando comparadas ao sistema em $\mathrm{pH} 7$, as partículas GlyCHI/TPP produzidas em $\mathrm{pH} 4$ apresentaram um valor de PDI muito menor e um valor de potencial zeta maior e positivo, como desejado. Isso pode ser justificado pelo fato de 
que, em meio ácido, os grupamentos amina do polímero estão protonados e mais disponíveis para a interação eletrostática com os grupamentos fosfato do TPP. Em decorrência do aumento de diâmetro médio das partículas em pH 4, estudou-se como a concentração final de GlyCHI influencia no tamanho das partículas a fim de se obter os melhores parâmetros operacionais do processo.

\subsection{Estudo da concentração final de GlyCHI em pH 4}

A partir dos resultados obtidos nos itens anteriores, realizou-se um estudo da concentração final de GlyCHI. Esse estudo teve como objetivo encontrar a maior concentração de GlyCHI que permita a formação de nanopartículas com propriedades físicoquímicas adequadas. Dessa forma, foram produzidas nanopartículas de GlyCHI/TPP mantendo-se $\mathrm{R}_{\mathrm{GlyCH} / \mathrm{TPP}}$ igual a 2, com pH das soluções de água, GlyCHI e TPP iguais a 4. A caracterização físico-química das amostras coletadas encontra-se nas Figuras 4 (A) e 4 (B).

Figura 4 - Valores de (A) Diâmetro médio (nm) e PDI e (B) Potencial Zeta (mV) obtidos a partir de nanopartículas produzidas para diferentes valores de concentração final de GlyCHI com $\mathrm{R}_{\mathrm{CHI} / \mathrm{TPP}}$ igual a $2 \mathrm{em} \mathrm{pH} 4$.

(A)

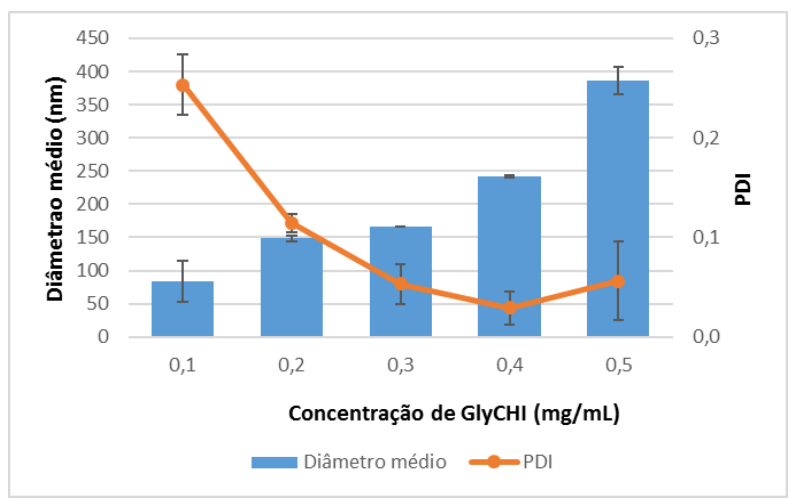

(B)

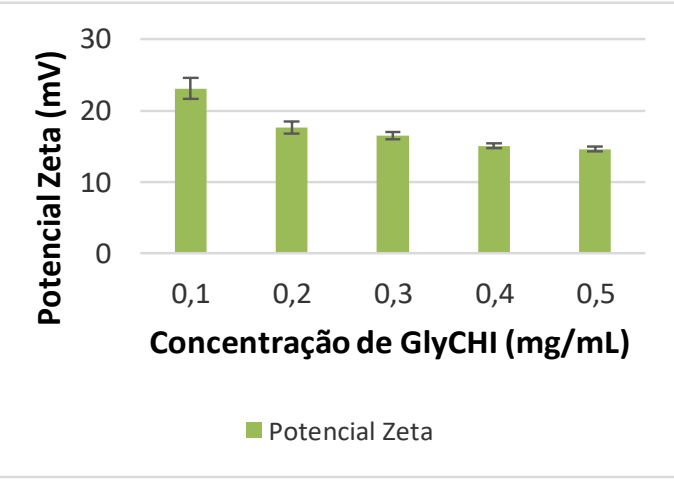

Pela análise da Figura 4 (A), pode-se observar que o tamanho das partículas tende a aumentar com o aumento da concentração de GlyCHI. Essa tendência é esperada porque uma maior concentração de GlyCHI no sistema favorece uma maior interação polímero-polímero (Evans e Wennerström, 1999), provavelmente levando o agente reticulante a complexar uma proporção mais alta de polímero por partícula, o que resulta em um maior tamanho de partícula.

Além disso, verificou-se que o PDI apresentou valores entre 0,25 e 0,03 , que são muito interessantes para aplicações futuras em nanomedicina. Para a concentração de $0,4 \mathrm{mg} / \mathrm{mL}$, foi obtido um valor de PDI de 0,03, indicando que a amostra é monodispersa, o que é desejável para garantir a reprodutibilidade da produção das nanopartículas.

Os valores de potencial zeta obtidos foram todos positivos, e observou-se uma diminuição do potencial zeta com o aumento da concentração de GlyCHI. Isso ocorre devido à maior interação polímero-polímero com o aumento da concentração, o que acarreta numa menor exposição das aminas protonadas da GlyCHI na disposição final das nanopartículas, resultando em uma carga superficial menos positiva (Bulmer et al., 2012). 


\section{CONCLUSÕES}

Os estudos realizados no presente trabalho demonstraram a produção de nanopartículas de GlyCHI/TPP a partir de um sistema microfluídico simples e com elevada reprodutibilidade. Embora a GlyCHI seja solúvel em $\mathrm{pH} 7$, fato que poderia contribuir para a aplicabilidade biológica das nanopartículas, a produção em $\mathrm{pH} 4$ mostrou-se mais favorável para a produção de nanopartículas de GlyCHI/TPP com baixa polidispersidade e potencialmente interessantes para aplicações em terapia gênica.

\section{REFERÊNCIAS}

BULMER, C.; MARGARITIS, A.; XENOCOSTAS, A. Production and characterization of novel chitosan nanoparticles for controlled release of $\mathrm{rHu}$-Erythropoietin. Biochem. Eng. J., v. 68, p. 61-69, 2012.

CARRILlO, C. et al. Chitosan nanoparticles as non-viral gene delivery systems: Determination of loading efficiency. Biomed. Pharmacother., v. 68, n. 6, p. 775-83, 2014.

EVANS, D. F.; WENNERSTRÖM, H. The Colloidal Domain: Where physics, chemistry, biology and technology meet. 2nd. ed. [s.l.] WILEY-VCH, 1999.

FAN, W. et al. Formation mechanism of monodisperse, low molecular weight chitosan nanoparticles by ionic gelation technique. Colloids Surfaces B Biointerfaces, v. 90, p. 21-7, 2012.

HASANI-SADRABADI, M. M. et al. Morphological Tuning of Polymeric Nanoparticles via Microfluidic Platform for Fuel Cell Applications. J. Am. Chem. Soc., v. 134, p. 1890418907, 2012.

JEONG, J. H.; KIM, S. W.; PARK, T. G. Molecular design of functional polymers for gene therapy. Prog. Polym. Sci., v. 32, n. 11, p. 1239-1274, 2007.

KARNIK, R. et al. Microfluidic platform for controlled synthesis of polymeric nanoparticles. Nano Lett., v. 8, n. 9, p. 2906-2912, 2008.

LA FUENTE, M. DE; SEIJO, B.; ALONSO, M. J. Bioadhesive hyaluronan-chitosan nanoparticles can transport genes across the ocular mucosa and transfect ocular tissue. Gene Ther., v. 15, n. 2008, p. 668-676, 2008.

LEE, D.-W.; POWERS, K.; BANEY, R. Physicochemical properties and blood compatibility of acylated chitosan nanoparticles. Carbohydr. Polym., v. 58, n. 4, p. 371-377, 2004.

STRAND, S. P. et al. Tailoring of chitosans for gene delivery: Novel self-branched glycosylated chitosan oligomers with improved functional properties. Biomacromolecules, v. 9, n. 11, p. 3268-3276, 2008.

WHITESIDES, G. M. The origins and the future of microfluidics. Nature, v. 442, n. 7101, p. 368-373, 2006.

YU, J.-M. et al. Self-aggregated nanoparticles of cholesterol-modified glycol chitosan conjugate: Preparation, characterization, and preliminary assessment as a new drug delivery carrier. Eur. Polym. J., v. 44, n. 3, p. 555-565, 2008. 